\title{
Ellipsis and Reiteration in English and Arabic: A Contrastive Study
}

\author{
Mohammad Jasim Betti ${ }^{1} \&$ Montadher Hussein Hameed AlFartoosy ${ }^{2}$ \\ ${ }^{1}$ Dept. of English/College of Education for Humanities, University of Thiqar, Iraq \\ ${ }^{2}$ Meisan Directorate of Education, Meisan, Iraq \\ Correspondence: Mohammad Jasim Betti, Dept. of English/College of Education for Humanities, University of \\ Thiqar, Iraq. E-mail: alseady2@gmail.com
}

Received: October 6, 2018 Accepted: November 11, 2018 Online Published: January 28, 2019

doi:10.5539/ells.v9n1p93 URL: https://doi.org/10.5539/ells.v9n1p93

\begin{abstract}
The present study is a descriptive contrastive one because it tries to give a full explanation of ellipsis and reiteration in English and Arabic to arrive at the similarities and differences between them. It deals with ellipsis and reiteration as processes by which a linguistic item is deleted or repeated. This is primarily achieved by showing their definitions, nature, types, and functions, and by surveying the literature available and by contrasting them in the two compared languages, conducting a contrastive study. The study finds out that ellipsis and reiteration as processes are found in both languages. In addition, it also finds out that ellipsis is more widely used than reiteration in both languages and that reiteration in Arabic is used more than in English. In this regard, the study shows that there are similarities and differences between English and Arabic but the area of differences is wider than that of similarities.
\end{abstract}

Keywords: ellipsis, reiteration, English, Arabic, a contrastive study

\section{Introduction}

\subsection{Introduce the Problem}

This study is a descriptive contrastive one. It studies and compares ellipsis and reiteration in English and Arabic contrastivey. It tries to give a full explanation of ellipsis and reiteration in English and Arabic in order to make a comparison between the two languages. Consequently, it is linguistic and applied since it shows an accurate linguistic description of the two languages in terms of ellipsis and reiteration. To the best of researcher's knowledge, ellipsis and reiteration in English and Arabic have not been studied contrastively, and the similarities and differences between the two languages are not shown in any other study.

The present study tries to answer the following questions:

1) What are the similarities and differences between ellipsis and reiteration in English and Arabic?

2) What are the syntactic and textual aspects of ellipsis and reiteration in the two languages?

3) How are the types of ellipsis and reiteration in both languages distinguished?

The study aims at:

1) Describing and comparing ellipsis in English and Arabic contrstively.

2) Describing and comparing reiteration in English and Arabic contrastively.

3) Showing to what extent the two languages are similar or different from each other in terms of ellipsis and reiteration.

To achieve the aims of the study, the following hypotheses are put. The first hypothesis states that ellipsis and reiteration as phenomena are found in both languages. The second hypothesis states that in English, ellipsis and reiteration exist in grammar and text while in Arabic, they exist only in text. The third hypothesis reads that the types of ellipsis in English are different from those of Arabic. The fourth hypothesis states that there are similarities and differences between the two languages, but the area of differences is wider than those of similarities. 


\subsection{Explore Importance of the Problem}

Studying ellipsis and reiteration in English and Arabic contrastively will help textbook designers in the compilation of textbooks to be studied by Iraqis learning English as a foreign language (EFL). Such contrastive studies will also help in solving some problems of the techniques used in teaching similar and/or different aspects of EFL.

\section{Describe Relevant Scholarship}

\subsection{Ellipsis in English and Arabic}

\subsubsection{Definition of Ellipsis}

In English and Arabic, ellipsis is the omission of one item from a sentence or a clause leaving the reader to conclude the omitted item when there is a verbal or mental evidence to that ellipted element. So, most definitions contain terms such as omission of element which can be recovered or understood from context (linguistic or physical) (Alhaashimy, 1960, p. 224; Kroeger, 2005, p. 344; Crystal, 2008, p. 166).

\subsubsection{The Nature of Ellipsis}

According to Quirk et al. (1985, p. 883), ellipsis is regarded as grammatical omission in contrast to other types of omission. They add that ellipsis is a superficial phenomenon. Furthermore, words are omitted if they are particularly recoverable and this recoverability of words depends on the context.

Some kinds of ellipsis, which are not formal, are not dependent on the linguistic context. This means that the ellipted words cannot be recoverable from the context, as in, (you) Have a good time? The recoverability of the pronoun 'you' doesn't depend on the linguistic context of this statement (Quirk \& Greenbaum, 1973, p. 253).

Halliday and Hasan (1976, p. 4) state that ellipsis involves something left unsaid but understood. They mention that ellipsis is one of the cohesive devices that give a text the identity of being a text. These devices constitute the concept of cohesion. In addition, Carter (2006, p. 902) shows that ellipsis used both by speakers and writers and particularly in speech it can be regarded as a sign of informality. Halliday (1994, p. 310) adds that ellipsis is a distinctive feature of the conversation, as in the question answer sequence.

According to Halliday and Hasan (1976, p. 8), ellipsis is similar to substitution. They can be regarded as the same processes, but the mechanisms associated with ellipsis are genuinely complex. So, they are closely related, since ellipsis is substitution by zero. Haliday and Hasan (ibid) add that ellipsis is a variation on substitution. Taboada (2005, p. 5) shows that ellipsis is used more frequently than substitution. The speaker prefers to leave something (ellipsis) than to use a substitute term for it.

Generally, according to Halliday and Hasan (1976, p. 147), English has three types of ellipsis, nominal, verbal and clausal. As with ellipsis, substitution may be nominal, verbal and clausal (ibid, p. 88).

In Arabic, Abul makaarim (2007, p. 200) shows that ellipsis means deleting an element without changing its case. So, the ellipted element is known, in spite of its absence, since it is recoverable from the context. According to Aljaarim and Amiin (1999, p. 241). The speakers may delete what can be understood by the listener depending on a situational or mental evidence. Likewise, AlanSaary (1991, p. 692), adds that ellipsis is common in Arabic syntax where Arabs delete the sentence, the letter and the case vowel.

Marogy (2012, p. 121) shows that "the aim of ellipsis is brevity and economy, but it can only occur when the speaker is certain that the listener is able to recover the full meaning of the utterance and the omitted word."

Arab scientists state that ellipsis requires many conditions such as, the existence of a situational evidence, a reported speech, ellipsis should not be confirmed because it is contrary to confirmation and ellipsis should not lead to the shortness of the abbreviated element (AlanSaary, 1991, p. 692).

\subsubsection{Reasons of Ellipsis}

There are many reasons for ellipsis, by which, grammarians try to explain the phenomenon of ellipsis in its different places and types. These reasons are not mental and far from the reality of language, but are provisions or sequences derived by ancient people from the direct descriptive induction of language (Hammuudah, 1998, p. $31)$.

In English, the reasons include avoiding repetition, economy of component, continuation of thoughts and constituting the concept of cohesion (Halliday \& Hasan, 1976, p. 3; Robbins, 2007, p. 106). In contrast, in Arabic, the reasons of ellipsis include; frequent use, the length of speech, ellipsis for case, ellipsis for the word structure, regular reasons (phonetic or morphological), regular synthetic reasons, reduction, conciseness, extensiveness, glorifying what is vague, protecting the ellipted element from mentioning in a specific place to 
honour it, explanation after ambiguity, intending ambiguity, ignorance of the ellipted element, keeping the pause and feeling with eagerness and showing that time is shortened about saying the ellipted element (Hammuudah, 1998, pp. 31-107).

\subsubsection{Types of Ellipsis}

There are three types of ellipsis: nominal, verbal and clausal.

1) Nominal Ellipsis

Nominal ellipsis is the ellipsis that occurs within the nominal group where the noun or pronoun is deleted (Halliday \& Hasan, 1976, p. 147):

\section{A. Subject Ellipsis}

In English, it is possible to omit the subject of the coordinated clauses if it is identical within the clauses. In superordinate clauses, the ellipsis of the subject is generally not allowed (Qirk et al., 1972, p. 482; Broughton, 1990, p. 193):

(1) John sat down and (he) told us the news.

In Arabic, it is possible to omit the subject if it is previously mentioned. AlSaydaawy (1990) shows that the subject can be deleted if the context indicates it, even it is not mentioned:

(2) (Hattaa tawarat bilHijaabi) (Saad, p. 32) (Until it disappeared behind the veil) (Itani, 2012, p. 237)

Here, the assumed omitted subject is 'the sun', since the context indicates it.

\section{B. Object Ellipsis}

In English, according to Qirk et al. (1972, p. 490), the object can be deleted if the realized items are retained in the last clause. This type of ellipsis is usually cataphoric:

(3) Mary washed (the shirts), Jane ironed (the shirts), and Alice folded the shirts.

MaTluub (2006, p. 189) shows that the object can be omitted after the verb of volition 'will'. Furthermore, Aljirjaany (2004, p. 155) adds that the object may be omitted by the speaker intentionally and it is indicated by the context (see Appendix A):

(4) (walauu shaa?a lahadaakum Pajma9iina) (an-Nahl, p. 9)

(Had he willed, He could have guided you all.) (Itani, 2012, p. 133)

So the omitted object is 'your guidance' (hidaayatikum).

C. Auxiliary Ellipsis

In English, deleting the auxiliary is generally optional. It can be deleted in coordinated clauses if the subjects are different. However, in superordinate, it is generally not allowed to omit the auxiliary (Quirk \& Qreenbaum, 1973, p. 262):

(5) John should clean the shed and Peter (should) mow the lawn.

D. Predicate Ellipsis

Predicate ellipsis means the omission of the whole clause except the subject. In English, deleting the predicate is not common. However, predicate ellipsis occurs in constructions such as, comparative, coordinate and response constructions (Quirk et al., 1985, p. 906):

(6) Nigel finished the exam at the same time as George.

E. Ellipsis of the Subject Complement

In English, it is possible to omit the subject complement. The realized items must be in the last clause if the verb of this clause is not 'be' (Quirk \& Qreenbaum, 1973, p. 264):

(7) George has been (the chairman), and (George) obviously could again become the chairman.

F. Adverbial Ellipsis

In English, deleting the adverbial is not quite recurrent because the scope of adverbial is extended to the subsequent clauses than to say that is ellipted (ibid, p. 265). Furthermore, adverbial ellipsis can occur when the adverbial is process adjunct and it is realized in the last clause (ibid):

(8) Bill drinks (sparingly), and peter smoke sparingly. 


\section{G. Topic Ellipsis}

In Arabic, the topic can be deleted if it is singular (MaTluub, 2006, p. 194). There are many purposes for deleting the topic such as its appearance with evidence indication, narrowness of situation to lengthen the speech and preserving the rhyme (AlmaraGy, 2002, p. 90). In addition, topic ellipsis can be seen more in answering questions (AlanSaary, 1991, p. 723):

(9) (wamaa Padraaka maa hiyah, narun Hamiyah) (al-Qari'ah, pp. 10-11)

(And what will make you know what it is? (It is) a fiercely blazing fire) (Itani, 2012, p. 327)

\section{H. Comment Ellipsis}

In Arabic, the comment can be deleted more with 'negative laa for gender' and in answering questions (Hammuuda, 1998, p. 211; AlmaraGy, 2002, p. 92). There are many purposes for deleting the comment such as choose intention, trust by evidence of mind and indication on specialization:

(10) (qul law Pantum tamlikuuna khazaaina raHmati rabbii) (al-Isra, p. 100)

(Say, "If you possessed the treasuries of my Lord's mercy.") (Itani, 2012, p. 146)

\section{Adjective Ellipsis}

In Arabic, according to Ibin jinny (1990, p. 371) the adjective can be deleted if there is an evidence referring to it. The reason behind deleting the adjectiveis to praise highly and to glory the conjunctive noun (Alzarkashy 2001, p. 155):

(11) (falaa nuqiimu lahum yawmalqiyaamati waznan) (al-Kahf, p. 105)

(And on the day of Resurrection, we will consider them of no weight.) (Itani, 2012, p. 153)

J. Ellipsis of the Conjunctive Noun

In Arabic, according to ibin jinny (1991, p. 366), the conjunctive noun can be deleted if it is not vague and the adjective takes its place. Ibin Alathiir (1998, pp. 300-301) shows that the conjunctive noun can be deleted more in vocative. Alzarkashy (2001, p. 154) mentions two conditions for deleting the conjunctive noun: first, the conjunctive noun should have a special adjective referring to it and second, explaining the meaning should rely up on the adjective only:

(12) (waHamalnaahu 9alallwaaHin wadusurun) (al-Qamar, p. 13)

(And we carried him on a craft of planks and nails.) (Itani, 2012, p. 280)

So the omitted noun is 'ship' (safeena)

\section{K. Genitive Ellipsis}

In Arabic, according to Hammuuda (1998, p. 233), genitive can be deleted if there is an evidence referring to it. The evidence should be clear and should be understood by the listener. ibin Alathiir (1998, p. 297) shows that more than one genitive can be omitted in one sentence:

(13) (faqabiDhtu qabDhatan min Patharil-rasuuli) (TaaHa, p. 96)

(So, I grasped a handful from the messenger's traces.) (Itani, 2012, p. 162)

So the assumed omitted nouns are 'hoof'(Haafir) and 'horse'.

\section{2) Verbal Ellipsis}

In English, an elliptical verbal group implies words from a preceding verbal group. There are two types of verbal ellipsis, lexical ellipsis and operator ellipsis. Lexical ellipsis means deleting the lexical verb from the verbal group i.e., any verbal group not having a lexical verb is elliptical. Operator ellipsis, on the other hand, means deleting the subject and all the auxiliaries, except the lexical verb Halliday and Hasan (1976, p. 167):

(14) A: Have you been running?

B: Yes, I have.

(lexical ellipsis)

A: What have you been doing?

B: Running.

(operator ellipsis)

In Arabic, according to ibin Alathiir (1998, p. 285) verbal ellipsis is subdivided into two parts. In the first part, the verb appears by object indication. In the second part, the verb can be inferred from the context. Furthermore, AlanSaary (1991) shows that verbal ellipsis is common in the answering questions: 
(15) (faqaalalahum rasuulullaahi naqatallaahi wasuqyaahaa) (ash-Shams, p. 13)

(The messenger of God said to them, "this is the she-camel of God. So let her drink.") (Itani, 2012, p. 323)

So, the assumed omitted verb is 'irrigate' (yasqy) (isquu naqtal lahi)

3) Clausal Ellipsis

In English, Clausal ellipsis occurs if either the model element or propositional one is omitted (Halliday \& Hasan, 1976, p. 197):

(16) A: Who was going to plant a row of poplars in the park?

B: The Duke was (going to plant a row of poplars in the park).

In Arabic, clausal ellipsis means deleting the whole clause and is more common than other types of ellipsis. Clausal ellipsis includes: ellipsis of the conditional sentence, condition answer sentence and verbal sentence muhammad (2010, p. 743):

(17) (fattabi9uunii yuHbibkumullaahu) (Al Imran, p. 31)

(Then follow me, and God will love you.) (Itani, 2012, p. 26)

So the origin is 'fain tataba9uuny yuHbibkum AllaH'

4) Ellipsis of the Letter

In Arabic, speakers tend to omit some letters, such as ellipsis of the propositional 'to', ellipsis of the propositional 'from', ellipsis of 'Albaa, ellipsis of 'Alalif' and ellipsis of 'vocative yaa' (ibin kathiir, 2004, p. 280; muhammed, 2010, p. 296):

(18) (sanu9iiduhaa siiratahal?ulaa) (Ta-Ha, p. 21)

(We will restore it to its original condition.) (Itani, 2012, p. 158)

\section{5) Positional Categories of Ellipsis}

In English and Arabic, there are three categories of ellipsis within the positional construction: initial, medial and final ellipsis. Initial ellipsis means the omission of an initial element, as in subject omission. Medial ellipsis means the omission of a medial element, as in verb omission. Final ellipsis means the omission of a final element, as in predicate omission (Quirk \& Greenbaum, 1990, p. 256; Quirk et al., 1985, p. 893).

\subsubsection{Types of Incohesive Ellipsis}

Quirk et al. (1985, p. 894) identify three types of ellipsis, textual, situational, and structural ellipsis.

\section{1) Textual Ellipsis}

Textual ellipsis, which means deleting items that are recoverable from linguistic context (Biber et al., 1999, p. 156), occurs when two clauses have components in common and these components are omitted in the second clause to avoid repeated items (Dowing \& Locke, 2006, p. 243). It can be divided, according to the position of ellipsis and its antecedent, into two types: anaphoric and cataphoric ellipsis. In anaphoric ellipsis, the interpretation relies on what precedes whereas in cataphoric ellipsis, cataphoric ellipsis the interpretation relies on what comes after (Quirk \& Greenbaum, 1990, p. 257).

\section{2) Situational Ellipsis}

Situational ellipsis, according to Biber et al. (1999, p. 104), means dropping of words with contextually low information value. These words come at the beginning of a turn, a clause or (occasionally) a non-clausal unit. Quirk et al. (1985, p. 895) state that in situational ellipsis the interpretation does not depend on a linguistic context.

Quirk et al. (ibid) show that situational ellipsis sometimes occurs in final position, but more typically it is initial, especially taking the form of omission of subject and/or operator.

3) Structural Ellipsis

In structural ellipsis, the interpretation depends on the syntactic knowledge of the structure as in the omission of the conjunction 'that' in, I believe (that) you are mistaken. Structural ellipsis includes the omission of elements such as determiners, pronouns, operators and other closed-class words in block language (Quirk \& Greenbaum, 1990, p. 257). 


\subsection{Reiteration in English and Arabic}

\subsubsection{Definition of Reiteration}

In English and Arabic, reiteration can be defined as a form of lexical cohesion that involves the repetition of a lexical item and includes the pronunciation and the meaning of that word. Reiteration may be achieved by using a general word, synonymy, near synonymy or a superordinate. (Halliday \& Hasan, 1976, p. 27; Almadany, 1996, p. 345).

\subsubsection{The Concept of Reiteration}

In English, reiteration includes the repetition of a lexical item, a general word referring back to a lexical item and the use of synonymy, near synonymy or superordinate (Halliday \& Hasan, ibid). Reiteration is considered as a stylistic feature of a writer since it mirrors the distinctive choices made by each writer (Gutwinski, 1976, p. 80).

In Arabic, reiteration is more widely used than in English. AlsayuuTy (2008, p. 553) shows that reiteration is a feature of fluency. He adds that there are many advantages to reiteration such as; decision, confirmation, increasing the warning, avoiding the obliviousness of speech, augmentation and intimation and separating repeated elements.

Alshimmary (2014, p. 103) shows that reiteration is an art of periphrasis where the speaker repeats an item for purposes such as, description, praise or dispraise. He adds that repetition may be of words or of vocables. Repetition of vocables is more widely used than of meaning. However, reiteration is of great significance in argumentative discourse so as to make cohesion and persuasion thoughts (ibid).

\subsubsection{Types of Reiteration}

In English, the types of reiteration include; repetition, synonymy, hyponymy, meronymy, and antonymy while in Arabic, it includes; direct repetition, synonymy, partial repetition, hyponymy and semi-repetition (Halliday \& Mathiessen, 2004, p. 571; Muhammad, 2009, p. 106).

\section{1) Repetition}

Repetition is the most direct form of lexical cohesion that occurs when a lexical item is repeated. Repeating the lexical item occurs either by full morphological repetition (total repetition) or by partial morphological repetition of the word stem or root (partial repetition) (Hoffmann, 2012, p. 87):

(19) And you will be happy to know that I could not have another cigarette if somebody paid me to smoke. There is some link in my brain between smoking and puking now, and so, I cannot even look at cigarettes.

(20) Yesterday I left a comment on JD's [...] past about chocolate. I said I had not eaten chocolate in years....

In (19) and (20), there are textual recurrences by form and meaning. In (19), there is partial repetition between the words 'cigarettes' and cigarette' and 'smoking' and 'smoke'. Example (20) provides total repetition between the words 'chocolate' and 'chocolate' (ibid).

In Arabic, repetition is referred to as a direct repetition (Muhammad, 2009). Direct repetition may be of words or of sentences. It may be of the same pronunciation but of different meaning or may be of the same pronunciation and of the same meaning (9afiify, 2001, p. 106):

(21) (fawaylun lillaDiina yaktibuuna lkitaaba bi?aydiihim thuma yaquuluuna haDaa min 9ind allaah liyashtarwa bihi thamanan qaliilan fawaylun lahum mimmaa katabat Paydihim wawaylun lahum mimmaa yaksibuuna) (al-Baqarah, p. 79)

(So woe to those who write the Scripture with their own hands, and then say, "This is from God," that they may exchange it for a little price. Woe to them for what their hands have written, and woe to them for what they earn.) (Itani, 2012, p. 6)

So, in this example, the word 'woe' is repeated directly without any change in the text.

2) Synonymy

In English, synonymy refers to the similarity of meaning between two or more items. Yule (2006, p. 104) states that words, which are synonymous, can often be substituted in sentences. He adds that the sameness of meaning between synonymous words is not always total i.e., there are certain situations in which synonymous words cannot be substituted for each other:

(22) What was his answer?

(23) What was his reply? 
So, the words 'answer' and 'reply' which are synonymous, are substituted for each other.

In Arabic, according to Khayrah (2015, p. 67), synonymy means the repetition of words that have the same meaning and different form. The purpose behind using synonymy is to avoid feeling of boredom and to catch the reader's attention. Ibin Alathiir (2007, pp. 165-166) states that synonymy is more common in Quran and eloquent speech:

(24) (Pallaahu laa Pilaaha Pillaa huwa alHayu lqayuumu) (al-Baqarah, p. 255)

(God there is no god except he, the living the everlasting.) (Itani, 2012, p. 21)

So, in this example the words 'the living' (alHay) and 'the everlasting' (alqayuum) are synonym. They have different form, but the same meaning. Both of them refer to 'God'.

3) Hyponymy

In English, according to Halliday and Hasan (1976, p. 280), hyponymy has been referred to as a superordinate. The relation of superordinate refers to any item in which the meaning includes the meaning of a preceding item, or any word that controls the preceding one in the lexical taxonomy:

(25) Henry has bought himself a new Jaguar. He particularly lives in the car.

So, the word 'car' refers back to the word 'Jaguar', and 'car' is a superordinate of 'Jaguar' which is a more general class.

In Arabic, hyponymy contributes to text cohesion since it includes the relation between vocables and meaning. In addition, hyponymy may cause a surprise to the reader who thinks that he reads a repeated element but it is a new one since it has a different meaningal9aayb (2014, p. 6):

(26) (hal jazaauliHsaani illaliHsaan) (ar-RaHman, p. 60)

(Is the reward of goodness anything but goodness?) (Itani, 2012, p. 283)

In this example, the words 'goodness' and 'goodness' have the same pronunciation but different meaning. The first one means 'well performance' (figil Hasin) whereas the second one means 'well retribution' (jazaa Hasin) (ibid).

4) Partial Repetition

In English, means repeating the same lexical item with no other than simple syntactic change (Hoffmann, 2012, p. 87):

(27) And you will be happy to know that I could not have another cigarette if somebody paid me to smoke. There is some link in my brain between smoking and puking now, and so, I cannot even look at cigarettes.

In (27), there is a partial repetition between the words 'cigarettes' and cigarette' and 'smoking' and 'smoke'.

In Arabic, partial repetition means repeating words and vocables that have the same root. Partial repetition depends on the root of the words. it is also has been referred to as a derivational repetition (Al-9aayib, 2014, p. 70):

(28) (?alraHmaani rraHymi) (al-Fatihah, 2) (The most gracious, the most merciful) (Itani, 2012, p. 1)

The words 'AlraHmaani' and 'AlraHymi' represent partial repetition since they are derived from the same root 'raHama' (Alfaqii, 2000, p. 26).

5) Meronymy

In English, meronymy, which the reverse of hyponymy, indicates the relation between an item and a more specific item (Halliday \& Mathiessen, 2004, pp. 575-576):

(29) Farida had a beautiful little glass scent-bottle. She had used up all the scent long ago; but she often used to take the little stopper out.

In this example, 'stopper' is Mronym of bottle since 'stopper' is a part of the whole 'bottle'.

6) Antonymy

In English, antonymy is the opposite of meaning between words. According to Halliday and Mathiessen (2004, p. 573), antonymy is a special case of synonymy and also functions with cohesive effect in a text:

(30) He fell asleep, what woke him was a loud crash.

In (30), the words 'asleep' and 'woke' have apposite meaning. So, a relation of antonymy exists between them. 


\section{7) Semi-Repetition}

In Arabic, semi-repetition refers to some similarity of pronunciation, not of meaning, between two or more words. semi-repetition occurs at the level of sound and contributes to text cohesion (9afiify, 2001, p. 110):

(31) (Palam naj9alil ParDha mihaadan, wajjibaala Pawtaada) (an-Naba, pp. 6-7)

(Did we not make the earth a cradle? And the mountains pegs) (Itani, 2012, p. 313)

\subsubsection{Other Types of Reiteration}

According to Dickins et al. (2002, pp. 100-111), repetition in can be divided into two kinds; lexical repetition and morphological repetition.

\section{1) Lexical Repetition}

In English, lexical repetition means repeating the same lexical item, general word referring back to a lexical item and the use of synonymy, near synonymy or superordinate (Halliday \& Hasan, 1976, p. 279):

(32) There is a boy climbing that tree. Most boys love climbing trees.

In Arabic, lexical repetition includes lexical item repetition and phrase repetition. Lexical item repetition means repeating the same word in a single sentence or in a text. It is used to serve two important functions: textual and rhetorical. Phrase repetition, on the other hand, means repeating the whole phrase in a text. It contributes to text cohesion Dickins et al. (2002, pp. 108-111):

(33) (kaana Paqrabumin Pabyhi Pillaal dunyaa, waPab9adu min Pabyhi ilaaldyn)

(He was nearer to life than his father, and farther to religious than him.)

This example provides an instance of lexical repetition where the word 'father' is repeated twice.

\section{2) Morphological Repetition}

In English, morphological repetition means repeating the same lexical item (Halliday \& Hasan, 1976, p. 278):

(34) There was a large mushroom growing near her, about the same height as herself; and, when she had looked under it, it occurred to her that she might as well look and see what was on the top of it.

She stretched herself up on tiptoe, and peeped over the edge of the mushroom, ...

So, (34) provides an instance of morphological repetition: mushroom refers back to mushroom.

In Arabic, morphological repetition includes pattern repetition, root repetition and suffix repetition. Pattern repetition means repeating the same pattern, as ( فاعل, faa9il, مفعول, maf9uul, fa9iil فعيل) in two or more words in close proximity. Root repetition involves the repetition of the same morphological root in close proximity within a text. The third type of morphological repetition is suffix repetition. It means repeating the same suffix at the end of words in close proximity (Dickins et al., 2002, pp. 100-111).

3) Incohesive Reiteration

Incohesive reiteration occurs within a sentence. Quirk et al. (1985, p. 1416) state that some items are repeated (either completely or by pronoun substitution) for emphasis or clarity. Hulst (2010, p. 48) describes incohesive reiteration as a motivated type of iteration where a word (normally a content word) is repeated in order to express meaning modulations such as intensification and augmentation.

\subsubsection{Functions of Reiteration}

In English, reiteration contributes to text cohesion since it helps the reader to recall a lexical item and associate it with another repetition of the same word (Guitwinski, 1976, p. 80). Furthermore, repetition has a stylistic function since it makes literary texts seem like everyday situations Tannen (2007, p. 8).

In Arabic, according to Dickins et al. (2002, p. 129) repetition supplies two functions. First, repetition may permit the writers to speak about linked ideas. Second, repetition may provide cohesive text-building function. Labidi (1992, p. 268) shows that repetition in Arabic has two functions: linguistic and rhetoric. Within linguistic function, repetition contributes to make the text more coherent. Within rhetoric function, on the other hand, repetition has tools such as persuasion, emphasis, assertion and assurance. However, Nazal (2009, p. 14) adds that repetition has functions such as, assurance, impedance, glorification and verification.

\subsection{Ellipsis and Reiteration in English and Arabic}

Ellipsis means deleting an item from a sentence or a clause leaving the reader to conclude the omitted item. Reiteration means repeating a lexical item. It occurs in English by using a general word, synonymy, 
near-synonymy or superordinate. In Arabic, it occurs when there is a verbal or mental evidence referring to it. On the other hand, ellipsis types are different from one language to another.

In English, generally, there are five types of cohesive ties: reference, substitution, ellipsis, conjunction and lexical cohesion. Lexical cohesion includes reiteration and collocation. So ellipsis and reiteration are cohesive devices that give a text the identity of being a text. These devices constitute the concept of cohesion. Ellipsis means deleting an item from a sentence or a clause leaving the reader to conclude the omitted item. The meaning of the ellipted word or phrase can be comprehended or recovered from the context. However, in speech, ellipsis is regarded as a sign of informality. Reiteration, on the other hand, means a form of lexical cohesion that involves the repetition of a lexical item, the use of general word to allude back to a lexical item and various things between the use of synonymy, near synonymy or superordinate. So the idea of reiteration includes not only repeating the same word but the occurrence of a related word, which may be a synonymy, near-synonymy or superordinate.

Halliday and Hasan (1976, p. 147) believe that there are three main types of ellipsis: nominal ellipsis, verbal ellipsis and clausal ellipsis whereas reiteration types include: repetition of the same word, synonymy, near-synonymy, hyponymy, meronymy and antonymy. So, there is a relation between ellipsis and reiteration since both of them are considered as cohesive devices that contribute to the text cohesion. Swan (2001, p. 14) adds that the end goal of ellipsis is to avoid reiteration, so, ellipsis is in contrary to reiteration.

In Arabic, there is no clear relation between ellipsis and reiteration but both of them contribute to the text cohesion. Ellipsis means deleting an element without changing its case. So, the ellipted element is known, in spite of its absence, since it is recoverable from the context. Within ellipsis, the speaker may delete what can be understood by the listener depending on a situational or mental evidence. Reiteration, on the other hand, means repeating a word or more than one word and this repetition includes the pronunciation and meaning of that word. There are some purposes to reiteration, such as, description, praise or dispraise whereas purposes of ellipsis include brevity and economy of speech.

There are five types of ellipsis in Arabic: nominal ellipsis, verbal ellipsis, clausal ellipsis, ellipsis of the letter and ellipsia of the case vowel whereas reiteration types include: repetition of the same word, synonymy, hyponymy, partial repetition and semi-repetition.

\section{Method}

This study is a descriptive contrastive one and the method of investigation in carrying out the starts with explaining ellipsis and reiteration in English and Arabic in terms of definitions, nature, types and functions. Then, the similarities and differences between the two languages in terms of ellipsis and reiteration are concluded.

In this regard, the Arabic examples, which are taken from glorious Quran, are translated to English according to Itani (2012) and Al-Hilali and Khan (2012), as well as transliterated by using Alphabetical Arabic symbols based on Betti (2007).

\section{Results}

To achieve the aims of the study, four hypotheses are put. The fist hypothesis states that ellipsis and reiteration as phenomena are found in both languages and it is proved that ellipsis and reiteration as phenomena are found in both languages and this supports the first hypothesis.

The second hypothesis states that in English, they exist in grammar and text while in Arabic, they exist only in text. It has been proved that ellipsis and reiteration exist in grammar and text in English, while in Arabic, they exist in text and this supports the second hypothesis.

The third hypothesis is put as follows: the types of ellipsis in English are different from those of Arabic. It has been proved that the types of ellipsis in English are different from those of Arabic and this supports the third hypothesis.

The fourth hypothesis, which states that there are similarities and differences between the two languages, but the area of differences is wider than that of similarities, is accepted.

\section{Conclusions}

This section deals with the similarities and differences between English and Arabic in ellipsis and reiteration, and it gives some recommendations for those who are concerned: 


\subsection{Similarities and Differences}

There are similarities and differences between ellipsis and reiteration in English and Arabic and this is shown below:

\subsubsection{Similarities}

The following similarities are drawn from the comparison of ellipsis and reiteration in English and Arabic:

In both languages, ellipsis involves the omission of one or more elements leaving the reader to infer the omitted element and this recoverability depends on the context. Likewise, ellipsis contributes to text and sentence cohesion and it is used to avoid repetition. In this regard, subject, object, verbal, clausal, initial medial, and final ellipsis occur in both languages.

Verbal ellipsis is subdivided into parts in both languages. In English, it includes: lexical and operator ellipsis., In Arabic, in the first part, the verb appears by the object indication while in the second part, the verb can be inferred from the context.

In both languages, reiteration involves repeating item(s), and contributes to text cohesion. Repetition of the same lexical item, synonymy and hyponymy, and partial ellipsis is considered a type of reiteration in both languages.

\subsubsection{Differences}

In English, ellipsis is regarded as a grammatical omission and there is a reference to auxiliary ellipsis while in Arabic the cases are different as ellipsis is omission in morphology and syntax and there are no auxiliaries in the way they correspond to in English.

In Arabic, there are references to topic ellipsis and comment ellipsis, while in English there are references to a predicate ellipsis, subject ellipsis, of incohesive ellipsis; textual, situational and structural ellipsis only. Likewise, Arabic treats ellipsis of the conjunctive noun as a type of nominal ellipsis and it has ellipsis of the letter as a type of ellipsis. Similarly, in Arabic, morphological repetition includes, pattern, root and suffix repetition while in English, it includes lexical item repetition.

English reiteration is considered as a stylistic feature of the writer while in Arabic, reiteration is considered a feature of fluency. In addition, English treats meronymy and antonymy as types of reiteration while Arabic does not treat them in this way.

English grammarians deal with ellipsis and reiteration as grammatical topics and as cohesive devices while Arabic grammarians deal with them superficially. English has three types of ellipsis: nominal, verbal and clausal ellipsis while Arabic has five types: nominal, verbal, clausal, ellipsis of the letter, and ellipsis of the case vowel.

Reiteration in Arabic is more widely used than in English (Karoly, 2007, p. 78). The reasons behind using ellipsis in Arabic are more than those in English, and the functions of reiteration in Arabic are more than those in English.

\subsection{Recommendations}

The recommendations arrived at in this study include the following.

There ought to be a textbook about contrastive studies and TOEFL test to be taught to the undergraduate students who learn second language at the universities. The difference in using ellipsis and reiteration in English and Arabic ought to be taken into consideration in the pedagogical process.

EFL designers out to give the learners a clear account of ellipsis and reiteration showing their types and functions, and EFL teachers ought to be specialized in teaching contrastive studies.

\section{Acknowledgements}

We thank Almighty Allah for giving us the courage and determination, as well as guidance in conducting this study despite all difficulties. We would like also to extend our thanks to all those authors from whose articles we take quotations. Heartly, we owe a great deal of thanks to all those who provided us with sources and those who give us pieces of advice. Also we would like to thank our colleagues of English department, for their continuous encouragement and support.

\section{References}

Abuu A. A. (2007). Ellipsis and Estimation in Arabic Syntax. Cairo: Gariib Publication House.

Al-Haashimy, A. (2005). Rhetoric Essences in meaning, eloquence and ingenuity. Beirut: Alfikr Publication House. 
Al-Hilali, M. T., \& Khan, M. M. (2012). Translation of the Meanings of The Noble Qur'an in the English Language. Madinah: King Fahd Glorious Qur'an Printing Complex.

Al-jirjaany, A. M. (1983). Definitions Dictionary. Cairo: AlfaDhiilah Publication House.

Al-madany, I. A. (1969). The Spring Gleams in Ingenuity Types. Alnajaf Alashraf: Alnu9maan Library.

Al-muraaGy, A. M. (2002). The Science of Rhetoric, eloquence and meanin. Beirut: Alktub Al9ilmyah Publication House.

AL-Saydaawy, Y. (1999). kafaaf Part 1. Demascus: Alfikr Publication House.

Al-sayuuTy, J. (2008). Perfection in Quranic Sciences. Beirut: Alrissalah Foundation.

Al-shimmary, H. M. (2014). 9izza's Kuthayr betwwen his old and modern Critics. Amman: Academic Writers Centre.

Al-zarkashy, B. A. (2001). Evidence in Quranic sciences (3rd ed.). Cairo: Altiraath Publication House.

Al-AnSaary, J. H. (1991). MuGnil labiib. Demascus: Alfikr Publication House.

Al-9aayb. (2014). The Effect of Lexical Link on Quranic Text Cohesion. Master Thesis: STiif University.

Baaklaa, M., \& Muhildiin, K. (1983). Dictionary of Modern Linguistics Terms. Beirut: Lebanon Library.

Betti, M. J. (2007). Jokes in Iraq: A Study of Coherence and Cohesion. Journal of the College of Education-University of Wasit, 1(1), 399-411.

Biber, D., Johansson, S., Leech, G., Conrad, S., \& Finegan, E. (1999). Longman Grammar of Spoken and Written English. Harlow: Longman.

Broughton, G. (1990). The Penguin English Grammar A.Z for Advanced Students. London: Penguin Books.

Carter, R., \& McCarthy, M. (2006). Cambridge Grammar of English. Cambridge: CUP.

Crystal, D. (2008). A Dictionary of Linguistics and Phonetics (5th ed.). Oxford: Blackwell publishing. https://doi.org/10.1002/9781444302776

Dickins, J., Hervey, S., \& Higgins, I. (2002). Thinking Arabic Translation. New York: Routledge Taylor and Francis Group.

Downing, A., \& Locke, P. (2006). English Grammar: A University Course (2nd ed.). New York: Routledge Taylor and Francis Group. https://doi.org/10.4324/9780203087640

Gutwinski, W. (1976). Cohesion in Literary Texts: A study of Some Grammatical and Lexical Features of English Discourse. The Hague: Mouton. https://doi.org/10.1515/9783111352176

Halliday, M. A. K., \& Mathiessen, C. M. I. M. (2004). An Introduction to Functional Grammar. London: Hodder Arnold.

Halliday, M. A. K., \& Hasan, R. (1976). Cohesion in English. London: Longman.

Hammuuda, T. (1998). Ellipsis Phenomenon in Linguistic Lesson. Aliskandaryah: Aldaar Aljaami9yah.

Hoffmann, C. (2012). Cohesive Profiling: Meaning and Interaction in Personal Weblogs. Amsterdam: John Benjamins Publishing Company

Hulst, H. V. D. (Ed.). (2010). Recursion and Human Language. New York: Mouton De Gruyter. https://doi.org/10.1515/9783110219258

Ibn A. D. (1998). Common Proverb in the Literature of the Writer and Editor. Beirut: Allkutub Al9ilmyah Publication House.

Ibn K. A. (2004). The Interpretation of the Holy Quran. Beirut: AlSafaa Library.

Ibrahiim, S. (2000). Text Linguistics Between Theory and Practice. Cairo: qibaa Publication House.

Itani, T. (2012). The Quran. Beirut: ClearQuran.

Khayrah, k. (2015). Hajaajyatil tikraar fi AlyaaDat iljazaair. Master Thesis.

Kroegr, P. (2005). Analysing Grammar: An Introduction. Cambridge: Cambridge University Press. https://doi.org/10.1017/CBO9780511801679

Labidi, A. H. (2009). Arabic Cultural/ Educational and Linguistic Background as Factors Effecting EFL Writing Performance. Ph. D. Thesis. Retrieved from http://usir.salford.ac.uk/id/eprint/2/88 
Marogy, A. E. (2012). The Foundations of Arabic Linguistics. Boston: Brill. https://doi.org/10.1163/9789004229655

MaTluub, A. (1999). Rhetoric and Application. Mousel: Ibn Al-athiir publication House.

Muhammad, A. S. (2009). Text Linguistics. Cairo: Arts Library.

Muhammad, Y. (2010). Ellipsis in Arabic. Journal in College of Basic Education, 2.

Nazzal, F. S. (2009). Repetition in Some of the Prophet's Hadiith: A Functionla Stylistic Study to a Style of the convenience Styles of the Prophet's Hadiith. Journal of Jordon Islamic Studies.

Quirk, R., \& Greenbaum, S. (1973). A University Grammar of English. London: Longman Group ULC LTD.

Quirk R., Greenbaum, S., Leech, G., \& Svartvik, J. (1972). A Comprehensive Grammar of the English. London: Longman

Robbins, L. (2005). Grammar and Style: At your Fingertips. New York: Penguin Group Inc.

Taboada, M. (2000). Cohesion as A Mesure in Generic Analysis. Retrieved from http://www.ucm.es/info/circulo/no3/taboada.htm

Tannen, D. (2007). Talking Voices: Repetition, Dialogue and Imagery in Conversational Discourse (2nd ed.). Cambridge: Cambridge University Press. https://doi.org/10.1017/CBO9780511618987

9afiify, A. (2001). Text Syntax: New Tendency in Linguistic Lesson. Cairo: Maktabat Alzahraa.

\section{Appendix A}

A List of Symbols of Arabic Phonemes (Betti, 2007)

\begin{tabular}{|c|c|c|c|}
\hline$/ \mathrm{f} /$ & as in & /fiil/ & 'an elephant' \\
\hline$/ \mathrm{th} /$ & as in & /thoor/ & 'ox' \\
\hline /D/ & as in & /Dubaabah/ & 'fly' \\
\hline$/ \mathrm{Dh} /$ & as in & /DhaabuT/ & 'officer' \\
\hline$/ \mathrm{s} /$ & as in & $/ \operatorname{sir} /$ & 'secret' \\
\hline$/ \mathrm{S} /$ & as in & /Sabur/ & 'patiance' \\
\hline$/ \mathrm{H} /$ & as in & /Hufrah/ & 'hole' \\
\hline $\mid \mathrm{z} /$ & as in & /zaara/ & 'visited' \\
\hline$/ \mathrm{ch} /$ & as in & /churbaayah/ & 'bed' \\
\hline$/ \mathrm{sh} /$ & as in & /shamaal/ & 'north' \\
\hline$/ \mathrm{kh} /$ & as in & /khubz/ & 'bread' \\
\hline /G/ & as in & /Graab/ & 'crow' \\
\hline$/ \mathrm{h} /$ & as in & /hala9/ & 'panic' \\
\hline$/ \mathrm{b} /$ & as in & /balad/ & 'country' \\
\hline$/ \mathrm{t} /$ & as in & /ta9liim/ & ‘education’ \\
\hline$/ \mathrm{T} /$ & as in & /Tawiil/ & 'long' \\
\hline$/ \mathrm{d} /$ & as in & /dub/ & 'bear' \\
\hline$/ \mathrm{k} /$ & as in & /kabiir/ & 'big' \\
\hline$/ \mathrm{q} /$ & as in & /qalb/ & 'heart' \\
\hline$/ \mathrm{R} /$ & as in & /Rataa/ & 'came' \\
\hline$/ \mathrm{j} /$ & as in & /jamal/ & 'camel' \\
\hline$/ \mathrm{m} /$ & as in & /maa?/ & ‘water’ \\
\hline$/ \mathrm{n} /$ & as in & /naajiH/ & 'successful' \\
\hline$/ \mathrm{w} /$ & as in & /waady/ & ‘valley’ \\
\hline$/ 1 /$ & as in & $/ \mathrm{liGz} /$ & 'puzzle' \\
\hline $\mid y /$ & as in & /yawm/ & 'day' \\
\hline /9/ & as in & /9alaa/ & 'on' \\
\hline$/ \mathrm{r} /$ & as in & /ramaa/ & 'threw' \\
\hline /i/ & as in & /mi9daa/ & 'stomach' \\
\hline /ii/ & as in & /kariim/ & 'generous' \\
\hline /aa/ & as in & /jamaal/ & 'beauty' \\
\hline /oo/ & as in & /tilifoon/ & 'telephone' \\
\hline$/ \mathrm{u} /$ & as in & /qutila/ & 'he is killed' \\
\hline /uu/ & as in & /9uud/ & 'stick' \\
\hline
\end{tabular}




\section{Copyrights}

Copyright for this article is retained by the author(s), with first publication rights granted to the journal.

This is an open-access article distributed under the terms and conditions of the Creative Commons Attribution license (http://creativecommons.org/licenses/by/4.0/). 